\title{
Migraine in 746 patients with multiple sclerosis
}

\author{
Enxaqueca em 746 pacientes com esclerose múltipla
}

Yara Dadalti FRAGOSO', Tarso ADONI², Soniza V. ALVES-LEON³, Samira L. APOSTOLOS-PEREIRA4, Marcos A. Diniz CARNEIRO ${ }^{5}$, Edila M. CHIKOTA6, Denise Sisterolli DINIZ5, Audred C. B. EBONI', Sidney GOMES ${ }^{8}$, Marcus Vinicius M. GONCCALVES', Ricardo Pereira GONCALVES ${ }^{10}$, José Luiz INOJOSA ${ }^{11}$, Thiago F. JUNQUEIRA' Suzana Costa MACHADO ${ }^{13}$, Fabiola Rachid MALFETANO ${ }^{14}$, Letícia Fezer MANSUR ${ }^{15}$, Maria Fernanda MENDES ${ }^{4}$, Andre MUNIZ16, Adaucto W. NOBREGA JUNIOR ${ }^{17}$, Guilherme Sciascia do OLIVAL ${ }^{18}$, Monica Fiuza PAROLIN ${ }^{19}$, Maria Lucia V. PIMENTEL ${ }^{15}$, Cristiane Franklin ROCHA ${ }^{20}$, Heloisa Helena RUOCCO ${ }^{21}$, Gutemberg C. SANTOS ${ }^{22}$, Fabio SIQUINELI²3, José Otavio D. SOARES ${ }^{24}$, Nise Alessandra C. SOUSA ${ }^{25}$, Carlos Bernardo TAUIL ${ }^{26}$, Thereza Cristina A. WINCKLER ${ }^{27}$

\begin{abstract}
Migraine adds to the burden of patients suffering from multiple sclerosis (MS). The ID-migraine is a useful tool for screening migraine, and the Migraine Disability Assessment questionnaire can evaluate disease burden. The aim of the present study was to assess the presence and burden of migraine in patients with MS. Methods: Patients diagnosed with MS attending specialized MS units were invited to answer an online survey if they also experienced headache. Results: The study included 746 complete responses from patients with MS and headache. There were 625 women and 121 men, and $69 \%$ of all the patients were aged between 20 and 40 years. Migraine was identified in 404 patients (54.1\%) and a moderate-to-high burden of disease was observed in $68.3 \%$ of the patients. Conclusion: Migraine is a frequent and disabling type of primary headache reported by patients with MS.
\end{abstract}

Keywords: Migraine; headache; multiple sclerosis.

\section{RESUMO}

Enxaqueca piora o sofrimento do paciente que tem esclerose múltipla (EM). ID-migraine é uma ferramenta útil para seleção de pacientes com enxaqueca e Migraine Disability Assessment (MIDAS) é um questionário que avalia o impacto da doença. O objetivo do presente estudo foi avaliar a presença e impacto de enxaqueca em pacientes com EM. Métodos: Pacientes diagnosticados com EM e tratados em clínicas especializadas foram convidados a responder um questionário online se também apresentassem cefaleia. Resultados: 0 estudo incluiu 746 participantes com cefaleia e EM que preencheram completamente as respostas. Foram 625 mulheres e 121 homens, sendo $69 \%$ dos pacientes com idade entre 20 e 40 anos. Enxaqueca foi identificada em 404 pacientes (54,1\%) e moderado a grave impacto da doença foi observado em 68,3\% dos casos. Conclusão: Enxaqueca é uma cefaleia primária frequente e incapacitante relatada por pacientes com EM.

Palavras-chave: Transtornos da enxaqueca; cefaleia; esclerose múltipla.

\footnotetext{
'Universidade Metropolitana de Santos, MS \& Headache Research, Santos SP, Brazil:

${ }^{2}$ Hospital Sírio-Libanês, São Paulo SP, Brazil;

${ }^{3}$ Universidade Federal do Estado do Rio de Janeiro, Rio de Janeiro RJ, Brazil;

${ }^{4}$ Hospital das Clinicas, Universidade de São Paulo, São Paulo, SP, Brazil;

5Universidade Federal de Goiás, Goiânia GO, Brazil;

${ }^{6}$ Saúde Global, Joinville SC, Brazil;

${ }^{7}$ Neurovie, Joinville SC, Brazil;

${ }^{8}$ Hospital Beneficência Portuguesa, São Paulo SP, Brazil;

`Universidade da Região de Joinville, Joinville SC, Brazil;

${ }^{10}$ Hospital Pompeia, Caxias do Sul RS, Brazil;

${ }^{11 U n i v e r s i d a d e ~ F e d e r a l ~ d e ~ P e r n a m b u c o, ~ R e c i f e ~ P E, ~ B r a z i l ; ~}$

${ }^{12}$ Escola Bahiana de Medicina e Saúde Pública, Salvador BA, Brazil;

${ }^{13}$ Neuroclinica, Florianópolis SC, Brazil;

${ }^{14}$ Universidade Federal do Rio de Janeiro, Rio de Janeiro RJ, Brazil;

${ }^{15}$ Santa Casa da Misericórdia do Rio de Janeiro, Rio de Janeiro RJ, Brazil;

${ }^{16}$ Clínica AMO, Salvador BA, Brazil;

${ }_{17}$ Universidade Federal de Santa Catarina, Florianópolis SC, Brazil;

${ }^{18}$ Santa Casa da Misericórdia de São Paulo, São Paulo SP, Brazil;
} 
Patients with multiple sclerosis (MS) are consistently reported as having a higher prevalence of headaches, particularly migraine ${ }^{1}$. The reason for this finding is yet to be clarified, but the predominance of inflammatory cytokines and adverse events from medications rate high among the potential causes of increased prevalence of headache among MS patients $^{2}$. In addition, demyelinating lesions in and around the periaqueductal grey area may be associated to (often intractable) headaches in patients with $\mathrm{MS}^{3,4}$. Adverse events relating to MS therapy may also account for the onset or worsening of migraine ${ }^{5,6}$.

The ID-Migraine is a simple three-item questionnaire that is used for screening migraine patients in primary care. However, it has only rarely been used in MS clinics ${ }^{7}$. It has been validated in several languages, including Brazilian Portuguese $^{8}$. Only one previous study has investigated the potential use of ID-Migraine among patients with $\mathrm{MS}^{9}$. In this previous Italian study, ID-Migraine showed high sensitivity (91\%) and specificity (94\%) for identifying migraine in 144 patients with MS. The burden of migraine was assessed using the Migraine Disability Assessment (MIDAS) ${ }^{10}$, in the Brazilian validated version ${ }^{11}$. The MIDAS has already been used in a few studies on migraine in MS identifying a moderate-to-high burden of disease ${ }^{12}$. Using these validated tools, the present study assessed headache in a population of Brazilian patients with MS.

\section{METHODS}

This was a cross-sectional study carried out in specialized MS units. Ethics Committee approvals were obtained in accordance with the rules and regulations of each participating MS center. Patients with MS attending regular consultations at these centers were invited to reply to an online questionnaire that sought clinical and demographic data, headache characterization, ID-Migraine data and MIDAS responses. The neurologists in charge of the patients told them about the study and its characteristics, and patients' associations in each region were informed of the national survey. The survey was set up in such a way that only the responses of patients who answered every question would be accepted for inclusion in the study. Nonetheless, these potential study participants were completely free to abandon the survey at all times. All information was obtained online without personal identification of patients: they were only asked to state their age, sex and number of years of formal schooling.

Patients with episodic and chronic migraine and tension-type headache were diagnosed in accordance with the criteria of the International Headache Society (ICDH-3 beta version $)^{13}$. Details of these patients' MS therapy were recorded. No healthcare professional had any influence on the responses that patients gave. Only patients with at least one year of confirmed diagnoses of MS were included in the study. The results are presented mainly in a descriptive manner.

\section{RESULTS}

Seven hundred and forty-six patients entered this study. The Table shows a summary of the results. There were 625 women and 121 men, and $69 \%$ of all the patients were aged between 20 and 40 years. The majority of the patients (97.6\%) had had 12 or more years of schooling and $70.9 \%$ of the sample were at university at the time or had already obtained a university degree. The duration of their MS was less than 10 years for $72.7 \%$ of all the patients. Migraine was identified in 404 patients with MS (54.1\%), and tension-type headache affected 320 patients with MS (42.9\%). Primary headache lasting longer than 15 days per month for more than three months was reported by 158 (21.1\%) patients. Moderate or severe pain during the headache attacks were reported by 499 patients (69.9\%). Headache identification was not possible in 22 patients and it was decided not to register "possible" or "probable" cases of a certain headache.

\footnotetext{
${ }^{19}$ Neurology Clinic, Curitiba PR, Brazil;

${ }^{20}$ Neurology Clinic, Belo Horizonte MG, Brazil;

${ }^{21}$ Universidade Federal Fluminense, Niteroi RJ, Brazil;

${ }^{22}$ Universidade Estácio de Sá, Rio de Janeiro RJ, Brazil;

${ }^{23}$ Hospital Santa Isabel, Blumenau SC, Brazil;

${ }^{24}$ Hospital Santo Ângelo, Santo Ângelo RS, Brazil;

${ }^{25}$ Hospital Universitário Getúlio Vargas, Manaus AM, Brazil;

${ }^{26}$ Universidade de Brasília, Brasília DF, Brazil;

${ }^{27}$ Universidade Positivo, Curitiba PR, Brazil

Yara Dadalti Fragoso (iD) https://orcid.org/0000-0001-8726-089X
}

Correspondence: Yara Dadalti Fragoso; Departamento de Neurologia da Faculdade de Medicina/UNIMES; Avenida Conselheiro Nébias, 536; $11045-002$ Santos SP, Brasil; E-mail:yara@bsnet.com.br

Conflict of interest: There is no conflict of interest to declare.

Received 17 March 2019; Received in final form 22 May 2019; Accepted 29 May 2019. 
Table. Summarized data on patients with multiple sclerosis (MS) and headache. Results are presented as percentage, and absolute values are found in the text.

\begin{tabular}{|c|c|}
\hline Variables & $\begin{array}{l}\text { Parameters } \\
(n=746)\end{array}$ \\
\hline \multicolumn{2}{|l|}{ Sex } \\
\hline Female & $83.8 \%$ \\
\hline Male & $16.2 \%$ \\
\hline \multicolumn{2}{|l|}{ Age group (years) } \\
\hline$\leq 45$ & $78.6 \%$ \\
\hline$>45$ & $21.4 \%$ \\
\hline \multicolumn{2}{|l|}{ Years of schooling } \\
\hline$\leq 12$ & $29.1 \%$ \\
\hline$>12$ & $70.9 \%$ \\
\hline \multicolumn{2}{|l|}{ MS disease duration (years) } \\
\hline$\leq 3$ & $63.9 \%$ \\
\hline$>3$ & $36.1 \%$ \\
\hline \multicolumn{2}{|l|}{ Had headache before MS? } \\
\hline No & $22.4 \%$ \\
\hline Yes & $77.6 \%$ \\
\hline \multicolumn{2}{|l|}{ Headache onset or worsening after MS diagnosis? } \\
\hline No & $52.5 \%$ \\
\hline Yes & $47.5 \%$ \\
\hline \multicolumn{2}{|l|}{ Headache onset or worsening due to MS treatment? } \\
\hline No & $44.6 \%$ \\
\hline Yes & $55.4 \%$ \\
\hline $\begin{array}{l}\text { Diagnosis of migraine by ID-Migraine and IHS } \\
\text { criteria }\end{array}$ & $54.1 \%$ \\
\hline Diagnosis of tension type headache by IHS criteria & $42.9 \%$ \\
\hline Unclassifiable headache & $3.0 \%$ \\
\hline Moderate or high disability by migraine (MIDAS) & $68.3 \%$ \\
\hline$\geq 15$ days per month of headache & $22.0 \%$ \\
\hline
\end{tabular}

The ID-Migraine identified 409 individuals as migraineurs in this study. Using the ICDH-3 criteria, 404 patients with MS had all the necessary symptoms for diagnosing migraine. Thus, ID-Migraine presented $98.2 \%$ specificity, since five patients could be classified as having tension-type headache according to the IHS criteria but were identified as having migraine using this tool. The questionnaire showed $100 \%$ sensitivity, since no patients with migraine were identified using the ICDH-3 criteria that were not already identified through ID-Migraine.

The MIDAS identified 276 cases of moderate or high disability among the 404 patients with migraine (68.3\%). Migraine attacks were described as occurring on 7-15 days per month in 102 patients ( $25.2 \%$ of the migraineurs) and on more than 15 days per month in another 49 patients (12\% of the migraineurs), and the presence of continuous headache was reported by a further 40 patients with MS (10\% of the migraineurs). In summary, $47.2 \%$ of the patients with migraine and MS had at least seven days of pain per month.

Acetaminophen was the medication of choice for treating headache attacks for $36.1 \%$ of the patients, while $43.8 \%$ made use of metamizole sodium. Non-steroidal anti-inflammatory drugs were used by $34.3 \%$ of the patients. Oral tablets with ergot and caffeine were used by $30.6 \%$ of the patients who did not respond to the above-mentioned analgesics or antiinflammatory drugs. For refractory pain, triptans were used by $8.6 \%$ of the patients, while tramadol was used by $11.3 \%$. All of these medications were often used in association with or in sequence for the same attack.

Prophylactic treatment with beta-blockers, topiramate, valproate or tricyclic drugs had been prescribed for $32.6 \%$ of the patients. Antidepressants, anti-anxiety drugs and other unspecific drugs had been used as preventive treatment for $21.1 \%$ of the patients. However, this study was not designed to evaluate the effect of therapy among patients with MS.

Onset or worsening of headache episodes at or soon after receiving the diagnosis of MS was reported by 354 patients $(47.5 \%)$. Interferon beta was prescribed at some point during the therapy for 457 patients with MS in these units. Irrespective of the mode of administration of this drug (subcutaneously or intramuscularly), the use of interferon beta led to the onset or worsening of headache in 266 patients (58.7\% of those who used interferon beta at any point). On the other hand, glatiramer acetate was prescribed for 344 patients with MS at some point in their treatment and led to headache as an adverse event in $14.4 \%$ of these individuals. Fingolimod led to the onset or worsening of previous headaches in $73.1 \%$ of 208 patients who received this treatment at any time, while natalizumab was reported to worsen headache in $58 \%$ of 190 patients who were treated with this monoclonal antibody. Glatiramer acetate was the drug least related to headache as an adverse event ( $p<0.001$ in comparisons with interferon beta, fingolimod and natalizumab). Other drugs had not been used in large enough numbers of patients to allow conclusions regarding headache triggering. There were only a few cases of patients using (or having used) teriflunomide, dimethyl fumarate, alemtuzumab or ocrelizumab, because of the reimbursement system within the Brazilian Ministry of Health protocol for treating MS. This study was not designed to identify which type of headache was associated with each of the treatments.

\section{DISCUSSION}

This large population study brought detailed information on headache affecting 746 patients with MS. The fivetimes higher prevalence of headache in women may be 
due to the higher prevalence of both MS and headaches in women. Only for a small number of patients $(<3 \%)$ was it not possible to classify their headache through the online questionnaire. A similarly low number of unclassified headache cases $(2 \%)$ was observed in a recent large Turkish study $^{14}$. The other patients in our study had either migraine or tension-type headache.

The ID-Migraine was a sensitive and specific tool for screening migraine in patients with MS. Only one study had previously used ID-Migraine among patients with MS, and that study showed that the prevalence of migraine was $53.5 \%$. In the present study, a similar prevalence of migraine was identified among patients with MS.

The ID-migraine is an easy-to-use self-applicable test that can be routinely used in specialized MS centers. With this simple tool, patients in need of special attention for their headache can be identified and treated. Multiple sclerosis clinics tend to concentrate efforts on maintaining good neurological function, through assessing mobility, coordination, visual function, cognition, control of neuropathic pain (such as trigeminal neuralgia) and sphincter ability, but may not have any specific programs for attending to primary headaches. Both MS and migraine can negatively influence patients' quality of life, mood, sleep and cognition.

The burden of migraine in patients with MS was shown to be moderate or high in nearly $70 \%$ of these migraineurs. About a quarter of the migraineurs with MS suffered from headache attacks on 7-14 days every month. Over $21 \%$ of the migraineurs with MS had between 15 and 30 days of pain per month. The pain intensity was described as moderate or high in over $68 \%$ of the patients enrolled in this study.
Most of the patients used analgesic and anti-inflammatory drugs to treat their attacks and less than one third of them had received prophylactic treatment for migraine. The dosage, duration and adherence to these prophylactic drugs was not established through the present study. Almost all the patients with MS participating in the present study treated their headache attacks mainly with painkillers and antiinflammatory drugs. This finding is in agreement with that reported by Villani et al. ${ }^{12}$, who also reported that the use of triptans by these patients was remarkably rare. These authors showed that less than $10 \%$ of the patients had received prophylactic treatment for their migraine. In the present report, a larger number (nearly one third of all migraineurs) had received prophylaxis. However, the dose, duration and efficacy of these preventive therapies cannot be assessed through the methodology used here.

Interferon beta, fingolimod and natalizumab seemed to increase the frequency and severity of headaches in patients with MS. Interferon beta has systematically been reported to be a triggering or worsening factor for migraine in patients with $\mathrm{MS}^{5,6,15}$. The present study identified headache as a frequent adverse event of both fingolimod and natalizumab. In making therapeutic choices, these findings need to be considered, as some adverse events may deter the patients' adherence to MS therapy. It is important to address migraine in patients with MS when aiming for a holistic approach to the well-being of people under neurologists' care ${ }^{16,17}$.

In conclusion, migraine is a frequent and disabling condition in patients with MS. An adequate approach towards controlling both diseases is paramount if quality of life and adherence to treatment are sought.

\section{References}

1. La Mantia L, Prone V. Headache in multiple sclerosis and autoimmune disorders. Neurol Sci. 2015 May;36(S1 Suppl 1):75-8. https://doi.org/10.1007/s10072-015-2146-9

2. Putzki N, Katsarava Z. Headache in multiple sclerosis. Curr Pain Headache Rep. 2010 Aug;14(4):316-20. https://doi.org/10.1007/s11916-010-0126-6

3. Fragoso YD, Brooks JB. Two cases of lesions in brainstem in multiple sclerosis and refractory migraine. Headache. 2007 Jun;47(6):852-4. https://doi.org/10.1111/j.1526-4610.2007.00823.x

4. Gee JR, Chang J, Dublin AB, Vijayan N. The association of brainstem lesions with migraine-like headache: an imaging study of multiple sclerosis. Headache. 2005 Jun;45(6):670-7. https://doi.org/10.1111/j.1526-4610.2005.05136.x

5. Villani V, Prosperini L, De Giglio L, Pozzilli C, Salvetti M, Sette G. The impact of interferon beta and natalizumab on comorbid migraine in multiple sclerosis. Headache. 2012 Jul-Aug;52(7):1130-5. https://doi.org/10.1111/j.1526-4610.2012.02146.x

6. Patti F, Nicoletti A, Pappalardo A, Castiglione A, Lo Fermo $S$, Messina $S$, et al. Frequency and severity of headache is worsened by Interferon- $\beta$ therapy in patients with multiple sclerosis. Acta Neurol Scand. 2012 Feb;125(2):91-5. https://doi.org/10.1111/j.1600-0404.2011.01532.x
7. Lipton RB, Dodick D, Sadovsky R, Kolodner K, Endicott J, Hettiarachchi J, et al. A self-administered screener for migraine in primary care: the ID Migraine validation study. Neurology. 2003 Aug;61(3):375-82. https://doi.org/10.1212/01.WNL.0000078940.53438.83

8. Mattos AC, Souza JA, Moreira PF, Jurno ME, Velarde LG. ID-Migraine ${ }^{\mathrm{TM}}$ questionnaire and accurate diagnosis of migraine. Arq Neuropsiquiatr. 2017 Jul;75(7):446-50. https://doi.org/10.1590/0004-282×20170069

9. Villani V, Prosperini L, Pozzilli C, Salvetti M, Ciuffoli A, Sette G. The use of ID migraine ${ }^{T M}$ questionnaire in patients with multiple sclerosis. Neurol Sci. 2011 Apr;32(2):269-73. https://doi.org/10.1007/s10072-010-0443-x

10. Stewart WF, Lipton RB, Kolodner KB, Sawyer J, Lee C, Liberman JN. Validity of the Migraine Disability Assessment (MIDAS) score in comparison to a diary-based measure in a population sample of migraine sufferers. Pain. 2000 Oct;88(1):41-52. https://doi.org/10.1016/S0304-3959(00)00305-5

11. Fragoso YD. MIDAS (Migraine Disability Assessment): a valuable tool for work-site identification of migraine in workers in Brazil. Sao Paulo Med J. 2002 Jul;120(4):118-21. https://doi.org/10.1590/S1516-31802002000400006 
12. Villani V, De Giglio L, Sette G, Pozzilli C, Salvetti M,

Prosperini L. Determinants of the severity of comorbid migraine in multiple sclerosis. Neurol Sci. 2012 Dec;33(6):1345-53. https://doi.org/10.1007/s10072-012-1119-5

13. Headache Classification Committee of the International Headache Society (IHS) The international classification of headache disorders, 3rd ed (beta version.) Cephalalgia. 2013;33(9):629-808. https://doi.org/10.1177/0333102413485658

14. Beckmann Y, Türe S. Headache characteristics in multiple sclerosis. Mult Scler Relat Disord. 2019 Jan;27:112-6. https://doi.org/10.1016/j.msard.2018.09.022
15. Khromov A, Segal M, Nissinoff J, Fast A. Migraines linked to interferon-beta treatment of multiple sclerosis. Am J Phys Med Rehabil. 2005 Aug;84(8):644-7. https://doi.org/10.1097/01.phm.0000171012.86932.10

16. Kister I, Caminero AB, Monteith TS, Soliman A, Bacon TE, Bacon JH, et al. Migraine is comorbid with multiple sclerosis and associated with a more symptomatic MS course. J Headache Pain. 2010 Oct;11(5):417-25. https://doi.org/10.1007/s10194-010-0237-9

17. Saylor D, Steiner TJ. The global burden of headache. Semin Neurol. 2018 Apr;38(2):182-90. https://doi.org/10.1055/s-0038-1646946 